\title{
Job crafting as a mediator between situational factors and well-being at work among outbound call centre operators in Peru
}

\author{
Sandra Corso de Zúñiga ${ }^{1}$, Luis Antonino Lazarte Aranguren² \\ ${ }^{1}$ Pacífico Business School, Jirón Sánchez Cerro 2121, Jesús María, Lima, Perú \\ ${ }^{2}$ Universidad Privada del Norte, Avenida Andrés Belaunde cdra. 10, Comas, Lima, Perú
}

Recibido 15 de noviembre del 2018, Revisado el 22 de marzo de 2019

Aceptado el 25 de abril de 2019

DOI: https://doi.org/10.33017/RevECIPeru2019.0002/

\section{Resumen}

En este estudio, se analiza el papel explicativo del rediseño del propio trabajo (job crafting) en la relación entre las demandas situacionales (demandas y recursos laborales) que enfrenta el trabajador y su bienestar. Los participantes del estudio fueron 518 operadores de tres centros de contacto de tamaño pequeño y mediano en Perú. Para ello nos basamos en el modelo de Demandas-Recursos laborales. Nuestra hipótesis principal sostiene que a pesar que los centros de llamadas son entornos de trabajo muy estructurados y controlados, los operadores rediseñan sus trabajos y los adaptan a sus necesidades y capacidades, y éstas actividades a su vez tienen un impacto positivo en su bienestar laboral. Pusimos a prueba nuestras hipótesis utilizando modelos de ecuaciones estructuradas (SEM). Los resultados confirmaron las hipótesis y demostraron que, a pesar de tener un diseño de trabajo muy estructurado, las actividades de rediseño tienen un impacto positivo en el bienestar de los operadores, en términos de mayor energía, dedicación y concentración (engagement) y menor agotamiento y distanciamiento del trabajo (burnout). Los resultados de este estudio sugieren que los centros de llamadas de tamaño pequeño y mediano en países emergentes podrían aprovechar mejor sus limitados recursos y ofrecer un entorno que facilite el rediseño de trabajo: proporcionando una adecuada retroalimentación (feedback), ofreciendo cierto nivel de autonomía, mejorando la comodidad en el trabajo y dando oportunidades para que el teleoperador desarrolle habilidades. Asimismo, se demuestró que el rediseño de trabajo disminuye el efecto de las demandas en el agotamiento, aunque en menor grado. Finalmente, discutimos las implicaciones de estos hallazgos.

Descriptores: Modelo de demandas y recursos laborales; engagement; burnout; job crafting; recursos laborales; demandas laborales.

\section{Abstract}

In this study, we analyse the mediation effect of job crafting in the relationship between situational demands (job resources and job demands) and well-being among 518 employees in three small to medium-sized outbound call centres in Peru using the Job Demands-Resources model as theoretical framework. Our primary hypothesis is that despite call centres being very structured and controlled work environments, call centre operators craft their jobs through stimulation from situational factors and adapt them to their needs and capabilities, and that these activities have a positive impact in their well-being at work. We test our secondary hypotheses simultaneously using structured equation modelling. The results confirm the hypotheses and demonstrate that despite having a very structured job design, job crafting activities have a positive impact on those call centre operators who engage in them, in terms of increased work engagement and decreased job burnout. The results of this study suggest that small to medium-sized call centres in emerging countries could leverage their limited resources by offering an environment that stimulates job crafting activities: providing feedback, autonomy, opportunities for development and comfort at work. Job crafting also explains the softer 
impact of job demands on job burnout, but in this case the effect was lower. We discuss the implications of these findings.

\section{Keywords: JD-R model, work engagement, job burnout, job crafting, job resources, job demands.}

\section{Introduction}

Call centres have become an important mechanism through which organisations communicate with their customers, users, and public. In the last decade, global call centre employment has risen significantly [1]. But despite their growth and importance, these work environments have been frequently associated with poor working conditions and employee ill-being. Indeed, call centre operators experience high levels of disengagement, job burnout [2-4] and voluntary turnover $[5,1]$.

Johnson et al. find that work-related stress in call centres is among the highest of all occupations [6]. This is hardly surprising, considering that several studies have argued that call centre employees have the worst job characteristics of any nonservice worker group $[7,8]$.

Rod \& Ashill highlight important differences between call centres, and that stressors at work are not the same from one to another. Traditionally, call centres are divided into two types: inbound and outbound. In the present study, we will focus our attention on operators of outbound call centres, whose primary activities are telemarketing and sales [9]. These operators need to be persuasive, flexible and emotionally intelligent to sell goods or services, but they must act within strict limits of autonomy and time in their sales efforts. Their job requires repetitive and often routine work, with limited task control [7].

To study ill-being and well-being at work we will refer to two opposite work-related states: job burnout and work engagement. Job burnout represents "a work psychological syndrome of two core dimensions such as exhaustion and cynicism" [10]. Employees who suffer job burnout are described as people with a lack of emotional resources and negative attitudes towards their own job [11]. Work engagement refers to "an active, positive and fulfilling psychological state characterized by vigour, dedication and absorption at work" [12]. Engaged employees are highly motivated individuals who channel their personal energies into physical, cognitive and emotional labours and are enthusiastically involved in their work [13].
Using the Job Demands-Resources model (JD-R model) as a framework, we will analyse two different processes in the workplace: the health impairment process and the motivational process. The former process proposes that job demands can turn into stressors that drain employees' physical, emotional, and cognitive energy reservoirs. The latter process represents the opposite, whereby job resources exert a motivational role and help employees deal with their job demands, so that they experience high levels of energy, dedication and enjoyment at work. The first process explains the development of the strain process related in ultimate state to job burnout and the second process explains the wellbeing process represented by work engagement.

Over the last decade, a great deal of research on call centres has focused on its job design and have analysed its effects on individual and organizational outcomes [14]. Yet few studies have attempted to understand how individuals cope with their job demands and successfully stay engaged with their job.

Zapf et al. point out that the problem many call centre operators face is not the excessive job demands, but the lesser presence of job resources that reduce the impact of stressors. We believe that those operators who manage to stay engaged and who report low levels of job burnout deliberately make some changes in their job to obtain the resources they need [7]. That is, as Tims \& Bakker demonstrate, employees can influence their job resources [15].

There is a need to explore further how these changes take place at an individual level in call centres. The job design in call centres is highly structured, so we believe that if operators want to adapt their job to their strengths or needs, they need to engage actively in to customizing it job in their favour. Sprigg \& Jackson find that the fewer opportunities call centre operators have to use their skills, the higher the level of strain they report. We expect individuals who play a more active role at their jobs to remain more engaged and experience less strain [14]. 
In recent years, there has been growing interest in job crafting as a complementary approach to the traditional job design framework. Job crafting brings a more comprehensive understanding of how employees face their working conditions and make proactive changes in order to balance their work experience with their own needs and expectations, and, as result, stay motivated and identified with their job [16].

In the present paper, we will study the mediational role of job crafting in the relationship between situational factors and well-being in outbound call centres operators in Lima, Peru, using as the JD-R model as a theoretical framework. Our aim is to study job crafting as an activity and to analyse its relationships with job demands and job resources as well as its consequences for well-being and illbeing, in order to gain a better understanding of how to increase work engagement and reduce job burnout. This is particularly important given that job resources for call centre operators in Peru are scarce; public organizations have pointed out that it is a business priority for Peruvian call centres to better develop job resources such as technical training, opportunities for development, and other human resources best practices in order to reinforce both business growth and the capabilities of their employees.

\subsection{The JD-R model}

\subsubsection{The energetic process in outbound call centres}

The energetic process predicts job burnout and its consequences in the workplace. Job burnout refers to "a psychological syndrome emerging as a prolonged response to stressors on the job" [17]. The core dimensions of burnout are exhaustion and cynicism [18]. Exhaustion represents the loss of energy, feelings of depletion, and complete weariness that the individual experiences at work [19]. Cynicism refers to the distance the individual puts between themselves and their work [11].

Rod \& Ashill find that outbound call centre operators differ from inbound call centre agents in the way they cope with exhaustion. Outbound call centre operators do so by assuming a cynical attitude at work. The authors attribute this cynicism to the rewards driven system, the sales focus, and the limited control that outbound call centres have on their interaction with the customers [9].
According to the JD-R model, the main predictors of job burnout are job demands [20]. Job demands are those physical, social or organizational characteristics that require sustained effort on the part of the employee to achieve, and are associated with physical and psychological costs for the individual [21]. It is important to stress that job demands are not negative by nature, but they can turn into stressors if the individual makes such an effort to meet these demands that they cannot easily recover [22].

Empirical research shows that emotional demands $[7,21]$ and work overload [2,14] are important stressors in call centres. Emotional demands refer to the emotionally charged situations that employees are required to face at work, while work overload alludes to the excessive workload that employees have to assume. In addition, hassles are associated with the difficulties employees have to overcome in order to do their work, such as red tape or administrative tasks.

We expect that the emotional demands, work overload and hassles experienced by outbound call centre operators will be directly associated with exhaustion and cynicism at work. Therefore, our first hypothesis is as follows:

H1. Job demands (job hassles, emotional demands and work overload) are positively associated with job burnout.

\subsubsection{The motivational process in outbound call centres}

The motivational process explains the antecedents: the individual and the organizational outcomes of work engagement. Work engagement is a positive work related-state that is represented by vigour, dedication and absorption [23]. Vigour refers to the high energy levels that employees display while working, as well as their mental resilience [24]. Dedication is characterized by the identification with the work one does and the sense of significance, pride and enthusiasm one gets from it [25]. Lastly, absorption relates to flow at work, the individual experiences focused attention, clear mind, effortless concentration and intrinsic enjoyment while working [25].

The JD-R approach holds that job resources are the main antecedents of work engagement $[25,26]$. Job resources refer to "those physical, psychological, social, or organizational aspects of the job that either/or (1) reduce job demands and 
the associated physiological and psychological costs; (2) are functional in achieving work goals; (3) stimulate personal growth, learning and development" [25]. The JD-R model highlights that job resources foster work engagement and reduce job burnout.

Mustosmäki, Anttila \& Oinas find that call centre agents experience less work engagement than employees from other service sectors such as retail, banking and insurance. This is not surprising since, as Zapf et al. (2003) previously pointed out, call centre work environments offer the lowest levels of job resources of the entire customer service field [27]. According to Mustosmäki el al., autonomy is the best predictor of work engagement in call centres, but call centres have the lowest levels of autonomy of all the service organizations they studied [27].

In the case of call centres in developing countries, those that provide resourceful working conditions are scarce. Call centres in Peru face many challenges, among them providing a comfortable place to work; for instance, the work spaces in Peruvian call centres have a high occupational density. In the present study we will include this variable as a job resource to analyse whether it has an impact on the well-being of the operators.

Most call operators are young and, for some of them, this is their first job. We will also include opportunities for development as a job resource to see whether the perception of having the possibility of learning new skills reinforces their other job resources.

Consequently, our second hypothesis is as follows:

H2. Job resources (autonomy, feedback, work environment and opportunities for development) are positively associated with work engagement.

\subsection{Job crafting in the JD-R model in outbound call centre operators}

Job crafting refers to "...the changes that employees may make to balance their job demands and their job resources with their personal abilities and needs" [28]. In broad terms, job crafting complements the traditional approaches to job design - which involve a top-down perspective whereby management is responsible for designing jobs - by recognising the bottom-up role of the proactive employee, and the capabilities with which they can craft their jobs [29]. Job crafting explains how employee well-being can be improved by nurturing the person-job fit between personal needs and abilities on the one hand; and job characteristics on the other [30].

Tims et al. describe four types of crafting activities: increasing structural job resources, increasing social job resources, increasing challenging job demands, and decreasing hindering job demands. They base these types on the JD-R framework, and provide measures for each [28].

For his part, Demerouti suggests that “...job crafting occurs in demanding, resourceful and changing work environments" [31]. However, Wrezsniewski \& Dutton observe that individuals "who work at levels of the organization in which freedom and creativity to craft are constrained might find that they are more motivated to work against these constraints by using job crafting as a vehicle for control" [30]. In fact, although call centres are characterised by offering low resources and for having a very structured job design, we expect call centre operators to engage in job crafting activities because this might offer them the possibility to stay engaged in their job and of protection against job burnout. Indeed, there is empirical evidence of job crafting in call centres. McClelland, Leach, Clegg \& McGowan find that operators who practiced collaborative crafting in their call centre teams experienced a higher level of work engagement among team members [32].

As Slemp et al. points out, "context matters for individual behaviours" [33]. Job crafting activities may be stimulated by situational factors such as job demands and job resources [34]. Basing their results on a 5-day diary survey, Petrou et al. find that on the days in which employees experienced higher work pressure and higher autonomy, they engaged more in job crafting activities [35].

Accordingly, we expect that outbound call centre operators in Peru will also practice job crafting activities stimulated by situational factors. Consequently, our third and fourth hypotheses are as follows.

H3. Job demands are positively associated with job crafting among outbound call centre operators.

$\mathrm{H} 4$. Job resources are positively associated with job crafting among outbound call centre operators.

1.3 The mediator effect of job crafting on work engagement and on job burnout 
Engaging in proactive behaviours and activities to shape one's job on the whole, has implications for job well-being. An increasing number of empirical studies have demonstrated a positive and predictive relationship between job crafting behaviours and work engagement. In a longitudinal study, Tims, Bakker \& Derks, demonstrate that employees who practiced job crafting behaviours in the form of seeking challenges and resources positively changed their work environment, thereby increasing their work engagement and decreasing burnout [28]. In another longitudinal study, Demerouti, Bakker \& Gevers find that the more resources individuals seek at work, the more engaged they are in their work [36]. Likewise, Harju, Hakanen \& Schaufeli employing a two-wave three-year design, show that seeking challenges positively predicted engagement among Finnish employees [37].

This results of these longitudinal studies are aligned with the COR theory that posits that "individuals must have the personal and environmental capacity to invest if they are to navigate and succeed at their engagement while they are dealing with life's every day or more major vicissitudes" [38]. We expect call centre operators to be stimulated by their resources at work and to engage in job crafting activities that will sustain their energy and enthusiasm at work, despite the rigid structure of their job design. In this regard, our fifth hypothesis is:

H5. Job crafting is positively associated with work engagement, thus playing a mediating role between job resources and work engagement.

Few studies have analysed the effect of job crafting on exhaustion and on job burnout. Oldman \& Fried have called for more research about job demands as predictors of job crafting, and about how job crafting outcomes affect job burnout. However, there are some empirical studies that illustrate this relationship [29]. Tims, Bakker \& Derks examine the different effects that job crafting activities have on employee well-being, reporting among their results a significant relationship between crafting in more challenging jobs and a decreased possibility of developing burnout in the case of employees of a chemical plant in The Netherlands [28]. Likewise, Petrou, Demerouti \& Schaufeli find that police officers who engaged in job crafting activities such as seeking resources and challenges were less likely to experience exhaustion [39].
We expect that the job resources the operators have at their disposal will stimulate job crafting activities, and these, in turn, will reduce the operators' prospects of developing burnout. Therefore, our sixth hypothesis is as follows:

H6. Job crafting is negatively associated with job burnout, thus playing a mediating role between job resources and job burnout.

Hobfoll points out that loss cycles and engagement may sometimes co-occur. However, as losses are more potent that gains, the loss cycle has to be contained in order to prevent the decline of the engagement cycle. In this case, there will be resource investment but this will involve a more conservative approach [40]. Hence, we expect that call centre operators who practice job crafting activities will be less likely to develop burnout, even though they are experiencing high job demands. Nonetheless, we believe this mediation effect will be weaker than the other mediations hypothesised.

Consequently, our final hypothesis is as follows:

H7. Job crafting is negatively associated with job burnout, thus playing a mediating role between job demands and job burnout.

\section{Method}

\subsection{Participants}

The present study was conducted among 518 outbound call centre operators who worked for three different telecommunications companies in Lima, Peru. Fifty-five percent of the participants were women. Nearly one quarter $(24 \%)$ of all participants were aged 18-19; $65 \%$ were aged 20 35 ; and the remaining $11 \%$ were aged $36-50$. About $83 \%$ of the operators had worked for the company for less than one year; and $12 \%$ for between one and two years. More than half of the operators were educated to secondary school level (56\%); $30 \%$ possessed a technical qualification; and $14 \%$ had completed their university studies.

\subsection{Procedure}

We emailed several outbound call centres operated by telecommunications companies in Lima, Peru and invited them to participate in the study. Three of the call centres agreed to take part in the research. After receiving their written acceptance, we requested a meeting with each of the site managers in their offices to explain the aims of the 
study and discuss the best way to address the operators. The questionnaire was distributed among the call centre operators via the intranet of each company. Each questionnaire included an information clause that explained the aims of the study, assured the confidentiality and anonymity of the responses, and stated that participation was voluntary. The response rate was nearly $70 \%$.

\subsection{Measures / Instruments.}

\subsubsection{Work engagement}

We assessed work engagement with the Spanish version of the Utrecht Work Engagement Scale (UWES), which is divided into three subscales: vigour, dedication and absorption [41]. Each subscale consists of three items scored on a seven-point Likert scale from 0 (never) to 6 (always). Example items from the vigour, dedication and absorption scales are "In my job, I feel strong and vigorous," "I am enthusiastic about my job" and "I feel happy when I am working intensely."

\subsubsection{Job burnout}

We assessed the dimensions of exhaustion and cynicism with the exhaustion scale from the Job Demands-Resources Questionnaire [42]. This scale consists of four items that are rated on a 5point Likert scale $(1=$ totally disagree, $5=$ totally agree). Example items from this subscale are: "During my work I often feel emotionally drained," and "After my work, I usually feel worn out and weary."

We assessed cynicism with the corresponding scale from the Spanish version of the Maslach Burnout Inventory. It consisted of five items scored on a 5 -point Likert scale ( $1=$ totally disagree, $5=$ totally agree). An example item from the scale is: "I have lost interest in my job since I started it."

\subsubsection{Job resources}

We assessed autonomy, feedback, and opportunities for development with the Job Demands-Resources Questionnaire [42]. The scales were scored on a five-point scale from 1 (totally disagree) to 5 (totally agree). Each of the scales consisted of three items. Example items from these scales are: "Do you have control over how your work is carried out?" "I receive sufficient information about the results of my work," and "In my work, I can develop myself sufficiently."
We assessed comfort at work with the corresponding scale from the Organizational Climate Questionnaire of the Peruvian Ministry of Health [43]. The scale is scored on a five-point Likert scale from 1 (totally disagree) to 5 (totally agree) and consists of three items. The items on these scale are: "The physical work environment is well organized in my area," "I feel that the physical distribution of my area allows me to work comfortably and efficiently", and "Generally speaking, I feel satisfied with my workspace."

\subsubsection{Job demands}

We assessed hassle, work overload, and emotional demands with the Job Demands-Resources Questionnaire [42]. The scales were scored on a five-point Likert scale from 1 (totally disagree) to 5 (totally agree). The scale of hassles consisted of five items. Example items from the hassles, work overload, and emotional demands scales are: "I have to get through a lot of red tape to get my job done," "Do you have to much work to do?" and "Do you face emotionally-charged situations in your work?".

\subsubsection{Job crafting}

We measured this variable with the Job Crafting Scale [44]. The scale consisted of 21 items and was scored on a five-point Likert scale rated from 1 (never) to 5 (very often). This scale is divided into four subscales: increasing structural job resources, increasing social job resources, increasing challenging job demands, and decreasing hindering demands. Sample items for increasing structural job resources are "I try to learn new things at work" and "I try to develop myself professionally". Sample items for increasing social job resources include "I ask colleagues for advice" and "I ask whether my supervisor is satisfied with my work," while sample items for increasing challenging job demands are "I regularly take on extra tasks even though I do not receive extra pay for them" and "I try to make my work more challenging by examining the underlying relationships between aspects of my job." Finally, a sample item for decreasing hindering demands is: "I organize my work so as to minimize contact with people whose expectations are unrealistic."

\section{Results}

\subsection{Data analysis}


First, we conducted the descriptive analysis using the SPSS 24 statistics software, and analysed the interrelations between the observed variables using the Pearsons correlation. We calculated the reliabilities of the scales using Cronbach's alpha coefficient. We again used SPSS 24 for the exploratory factor analysis (EFA), with maximum likelihood as the estimation method. We carried out both structured equation modelling (SEM) and multivariate analysis as a confirmatory factor analysis (CFA) using AMOS 24.

In preparation for the JD-R model, we checked for violations of assumptions of normality. We found univariate outliers at a proportion of less than $1 \%$ for the variables of work engagement and cynicism. In these cases, we applied the Winsorizing technique to reduce kurtosis.

Then, we employed EFAs to analyse the internal structure of the scales. Next, we employed CFAs to define the observed variables associated with the latent variables: job demands, job resources, job crafting, job burnout, and work engagement. The latent variable of job resources was indicated by autonomy, feedback, work environment, and opportunities for development $\left(X^{2}=148.66, d f=\right.$ $50, \mathrm{CFI}=.97, \mathrm{NFI}=.96, \mathrm{TLI}=.97 \mathrm{RMSEA}=.06$ ); job demands was indicated by work overload, emotional demands, and hassles $\left(X^{2}=115.04, d f=\right.$ $32, \mathrm{CFI}=.96, \mathrm{NFI}=.95, \mathrm{TLI}=.95$, RMSEA = .07); job burnout was indicated by exhaustion and cynicism $\left(\mathrm{X}^{2}=68.81, d f=18, \mathrm{CFI}=.97, \mathrm{NFI}=.97, \mathrm{TLI}=.96\right.$, RMSEA = .74); work engagement was indicated by the dimensions of vigour, dedication, absorption, and cynicism $\left(X^{2}=57.39 d f=24, \mathrm{CFI}=.99, \mathrm{NFI}=\right.$ .99, $\mathrm{TLI}=.99$, RMSEA = .52) . The AFC of job crafting with four dimensions had an unsatisfactory model fit $\left(X^{2}=959.23, d f=148, \mathrm{CFI}=.86, \mathrm{NFI}=.84\right.$, $\mathrm{TLI}=.84$, RMSEA $=.10)$. The model fit of job crafting improved when we excluded the dimension of decreasing hindering demands, $\left(x^{2}=317.63, d f\right.$ $=74, \mathrm{CFI}=.94, \mathrm{NFI}=.93, \mathrm{TLI}=.93, \mathrm{RMSEA}=.08$ ). The model fit in all the chosen variables was satisfactory.

After preparing the latent variables, we created the JD-R model (without job crafting) to verify that the assumptions of the job Demands-Resources model were met (hypotheses 1 and 2) and to observe whether there was a significant path from job resources to job burnout, which was confirmed $(\mathrm{Y}=$ $-.25, p<.001)$.

To test hypotheses 3-7, we introduced the latent variable of job crafting, which included three

dimensions (increasing structural job resources, increasing social job resources, and increasing challenging job demands) in the JD-R model. We tested hypotheses 3-7 simultaneously by conducting structural equation modelling analyses. We tested Hypothesis 3 by drawing a path from job demands to job crafting; and Hypothesis 4, by drawing a path from job resources to job crafting.

We tested the mediation effects of job crafting by analysing the standardised indirect effect of job resources on work engagement (Hypothesis 5); as well as the standardised indirect effect of job resources on job burnout (Hypothesis 6); and finally, the standardized indirect effect of job demands on job burnout (Hypothesis 7). We tested the significance of the mediational effect using the bootstrap technique with a $95 \% \mathrm{Cl}$ via calculation of 5000 bias-corrected samples.

We assessed model fit using incremental and absolute goodness-of-fit indices. Incremental measures of fit included the comparative fit index $(\mathrm{CFI})$, normed fit index (NFI) and non-normed fit index, or Tucker and Lewis index (TLI). Absolute measures of fit included the following: root mean square error of approximation (RMSEA) and standardized root mean square residual. Abad et al. (2011) propose that CFI, NFI and TLI values greater than .95 are considered a good fit, and that values between .90 and .95 are considered satisfactory. RMSEA values below .08 are considered satisfactory and SRMR values below .06 are considered a good fit.

\subsection{Descriptive statistics}

The means, standard deviations, reliabilities and correlations between study variables are displayed in Table 1. In general terms, we observe wide variability in the responses to the variables of vigour, dedication, and absorption in the case of work engagement. There is less dispersion in the responses to exhaustion and cynicism in the case of job burnout.

All the variables were correlated in the expected directions, with the exception of the job crafting dimension of reducing hindering demands, which is positively correlated to exhaustion and cynicism, and has no relationship with work engagement, job demands, or job resources.

\subsection{Model testing}


The indices of model fit for Model $1\left(X^{2}=144.37, d f\right.$ $=48, \mathrm{CFI}=.97, \mathrm{NFI}=.96, \mathrm{TLI}=.96, \mathrm{RMSEA}=.06$ ) and for Model $2\left(x^{2}=283.25, d f=80, C F I=.95\right.$, $\mathrm{NFI}=.93, \mathrm{TLI}=.93, \mathrm{RMSEA}=.07$ ) are presented in Table 2 . In both cases, the model fit is satisfactory [45].

The JD-R model assumptions were met in Model 1. Hypothesis 1 was confirmed, as there was a positive regression coefficient from job demands to job burnout $(\gamma=.60, \mathrm{p}<.001)$. Similarly, Hypothesis 2 was confirmed because there was a positive and significant regression coefficient from job resources to work engagement $(\gamma=.71, p<$
.001). There was also a significant and negative regression coefficient from job resources to job burnout $(y=-.25, p<.001)$. However, there was no significant relationship between job demands and work engagement. As expected, job demands and job resources were negatively correlated $(r=-.56, p$ $<.001$ ), as were job burnout and work engagement $(r=-.59, p<.001)$. We noted that the observed variables of emotional demands and work overload shared common variance, and given the strong theoretical reason for correlating them (both are challenging job demands), we proceeded to do so $(r=.42, p<.001)$.

Table 1. Means, standard deviations, reliabilities and correlations between variables

\begin{tabular}{|c|c|c|c|c|c|c|c|c|c|c|c|c|c|c|c|c|c|}
\hline Variable & $\mathrm{M} \pm \mathrm{SD}$ & $A$ & 1 & 2 & 3 & 4 & 5 & 6 & 7 & 8 & 9 & 10 & 11 & 12 & 13 & 14 & 15 \\
\hline 1. Vigour & $4.40 \pm 1.19$ & .86 & & & & & & & & & & & & & & & \\
\hline 2. Dedication & $4.57 \pm 1.33$ & .93 & $.83^{* *}$ & & & & & & & & & & & & & & \\
\hline 3. Absorption & $4.25 \pm 1.32$ & .87 & $.74^{* *}$ & $.81^{* *}$ & & & & & & & & & & & & & \\
\hline 4. Exhaustion & $2.43 \pm .69$ & .78 & $.42^{* *}$ & $.36^{* *}$ & $.33^{* *}$ & & & & & & & & & & & & \\
\hline 5. Cynicism & $1.76 \pm .64$ & .86 & $\begin{array}{l}- \\
.54\end{array}$ & $\begin{array}{l}- \\
.52^{* *}\end{array}$ & $-44^{* *}$ & $.52^{* *}$ & & & & & & & & & & & \\
\hline $\begin{array}{l}\text { 6. Emotional } \\
\text { demands }\end{array}$ & $2.29 \pm .96$ & .80 & $.20^{* *}$ & $.18^{* *}$ & $.16^{* *}$ & $.37^{* *}$ & $.29^{* *}$ & & & & & & & & & & \\
\hline 7. Job hassles & $2.33 \pm .92$ & .84 & $\begin{array}{l}- \\
.29^{* *} \\
\end{array}$ & $.25^{* *}$ & $.20^{* *}$ & $.37^{* *}$ & $.43^{* *}$ & $.41^{* *}$ & & & & & & & & & \\
\hline 8. Work overload & $2.63 \pm 1.05$ & .80 & $\begin{array}{l}- \\
.21^{* *}\end{array}$ & $.21^{* *}$ & $\begin{array}{l}- \\
.18^{* *}\end{array}$ & $.36^{* *}$ & $.26^{* *}$ & $.60^{* *}$ & $.42^{* *}$ & & & & & & & & \\
\hline 9. Feedback & $3.58 \pm 1.07$ & .89 & $.39^{* *}$ & $.38^{* *}$ & $.32^{* *}$ & $.22^{* *}$ & $.26^{* *}$ & $\begin{array}{l}- \\
.16^{* *}\end{array}$ & $.30^{* *}$ & $.14^{* *}$ & & & & & & & \\
\hline $\begin{array}{l}\text { 10. Work } \\
\text { environment }\end{array}$ & $3.23 \pm 1.04$ & .88 & $.41^{* *}$ & $.45^{* *}$ & $.41^{* *}$ & $.30^{* *}$ & $\begin{array}{l}- \\
.31^{* *} \\
\end{array}$ & $.22^{* *}$ &.$-36^{* *}$ & $.28^{* *}$ & $.42^{* *}$ & & & & & & \\
\hline 11. Autonomy & $3.62 \pm .98$ & .83 & $.47^{* *}$ & $.43^{* *}$ & $.42^{* *}$ & $.20^{* *}$ & $-32^{* *}$ & $.18^{* *}$ & $.29^{* *}$ & $-13^{* *}$ & $.53^{* *}$ & $.37^{* *}$ & & & & & \\
\hline $\begin{array}{l}\text { 12.Opportunities } \\
\text { for DVT }\end{array}$ & $3.78 \pm 0.86$ & .87 & $.51^{\star *}$ & $.56^{* *}$ & $.52^{* *}$ & $.26^{* *}$ & $.44^{* *}$ & $.24 *$ & $\begin{array}{l}- \\
.32^{* *}\end{array}$ & $.25^{* *}$ & $.48^{* *}$ & $.50^{* *}$ & $.56^{* *}$ & & & & \\
\hline $\begin{array}{l}\text { 13. JC } \\
\text { Challenging job } \\
\text { demands }\end{array}$ & $3.28 \pm 1.00$ & .91 & $.38^{* *}$ & $.33^{* *}$ & $.39^{* *}$ & -.07 & $.18^{* *}$ & ,07 & .00 & .02 & $.21^{* *}$ & $.16^{* *}$ & $.30^{* *}$ & $.28^{* *}$ & & & \\
\hline $\begin{array}{l}\text { 14. JC Structural } \\
\text { job resources }\end{array}$ & $4.31 \pm 0.79$ & .84 & $.60^{* *}$ & $.58^{* *}$ & $.51^{* *}$ & $-16^{* *}$ & $\begin{array}{l}- \\
.39^{* *}\end{array}$ & -.07 & -.08 & -.03 & $.27^{* *}$ & $.22^{* *}$ & $.38^{* *}$ & $.41^{* *}$ & $.48^{* *}$ & & \\
\hline $\begin{array}{l}\text { 15. JC Social job } \\
\text { resources }\end{array}$ & $3.07 \pm 1.05$ & .86 & $.37^{* *}$ & $.34^{* *}$ & $.37^{* *}$ & $.15^{* *}$ & $.18^{* *}$ & -.02 & $\begin{array}{l}- \\
.10^{*} \\
\end{array}$ & -.07 & $.38^{* *}$ & $.27^{* *}$ & $.33^{* *}$ & $.38^{* *}$ & $.62^{* *}$ & $.36^{* *}$ & \\
\hline $\begin{array}{l}\text { 16. JC Hindering } \\
\text { job demands }\end{array}$ & $2.97 \pm 1.12$ & .80 & .03 & .06 & .08 & $.12^{* *}$ & $.09^{*}$ & .06 & .05 & .04 & .04 & -.06 & .07 & .01 & $.34^{* *}$ & $.12^{* *}$ & 8 \\
\hline
\end{tabular}

The JD-R model assumptions were met in Model 1. Hypothesis 1 was confirmed, as there was a positive regression coefficient from job demands to job burnout $(Y=.60, \mathrm{P}<.001)$. Similarly, Hypothesis 2 was confirmed because there was a positive and significant regression coefficient from job resources to work engagement $(Y=.71, p<$ .001). There was also a significant and negative regression coefficient from job resources to job burnout $(\gamma=-.25, p<.001)$. However, there was no significant relationship between job demands and work engagement. As expected, job demands and job resources were negatively correlated $(r=-.56, p$
$<.001)$, as were job burnout and work engagement $(r=-.59, p<.001)$. We noted that the observed variables of emotional demands and work overload shared common variance, and given the strong theoretical reason for correlating them (both are challenging job demands), we proceeded to do so $(r=.42, p<.001)$.

Model 2 simultaneously tested hypotheses 3-7. Hypotheses 3 and 4 were confirmed as there were positive and significant paths from job demands to job crafting $(Y=.33, p<.001)$, and from job resources to job crafting $(y=.79, p<.001)$. 
The mediation effects of job crafting were confirmed (see Table 3). There were significant indirect effects of job resources on work engagement (Hypothesis 5) $(b=-.377, \mathrm{SE}=.057$, $p<.001$ ), and of job resources on job burnout (Hypothesis 6) $(b=-.313, \mathrm{SE}=.065, \mathrm{p}<.001)$. These effects indicated that job crafting activities partly explained the relationship between job resources and work engagement, and between job resources and work engagement. This means that job crafting behaviours and activities are associated with higher work engagement and lower job burnout among call centre operators, and in both cases the job resources of autonomy, feedback, comfort at work, and opportunities for development act as stimulators of job crafting activities.

The final hypothesis is also related to the mediation effects of job crafting in the JD-R model. However, in this case it analyses the indirect effect of job demands on job burnout (Hypothesis 7). The effect in this case is still significant, but it is weaker than in the other two mediations $(b=-.130, S E=.045, p$ $<.001)$. This indicates that the impact of job demands on job crafting is less powerful that the impact of job resources. However, call centre operators that practiced job crafting activities experienced less job burnout than the operators who did not engage in these activities.

Table 2. Research models

\begin{tabular}{|l|r|r|r|r|r|r|r|}
\hline Model & $\mathrm{X}^{2}$ & $d f$ & $C F I$ & $N F I$ & $T L I$ & SRMR & RMSEA \\
\hline M1. JD-R Model & 144.37 & 48 & .97 & .96 & .96 & .039 & .062 \\
\hline $\begin{array}{l}\text { M2. JD-R Model JC (3dimensions) } \\
\text { Alternative hypothesized model }\end{array}$ & 283.25 & 80 & .95 & .93 & .93 & .050 & .070 \\
\hline
\end{tabular}

Table 3. Indirect effects: estimates, standard errors, confidence intervals and two tail significance (BC)

\begin{tabular}{|l|r|r|r|r|r|}
\hline Relations/ Indirect effects & \multicolumn{3}{|c|}{$\begin{array}{r}\text { Bootstrap } \\
\text { analysis }\end{array}$} & \multicolumn{3}{|c|}{ Bias corrected confidence interval (95\%) } \\
\hline 1. Job resources $\rightarrow$ Job crafting $\rightarrow$ Engagement & .377 & .057 & .269 & .498 & $<.001$ \\
\hline 2. Job demands $\rightarrow$ Job crafting $\rightarrow$ Job burnout & -.130 & .045 & -.233 & -.056 & $<.001$ \\
\hline 3. Job resources $\rightarrow$ Job crafting $\rightarrow$ Job burnout & -.313 & .065 & -.450 & -.194 & $<.001$ \\
\hline
\end{tabular}

\section{Discussion}

As stated in the Introduction, our main aim is to study job crafting as an activity and to analyse its relationship with situational factors such as job demands and job resources, and its consequences for well-being and ill-being at work, using the JD-R model as framework. We conducted the study among 518 outbound operators from three small to medium-sized call centres in Lima, Peru - work environments characterized for being very controlled and structured with routine and repetitive tasks. We expected that call centre operators would engage in job crafting activities to enhance their well-being at work, even in a work environment that leaves little room for improvisation. Our results demonstrate that job resources (and job demands to a lower extent) stimulated job-crafting activities, and that these activities had a positive impact on the operators' work engagement and reduced their chances of developing job burnout. Therefore, job crafting acted as a mediator between situational factors and well-being at work.

The assumptions of the JD-R model were met in this study. The job demands of work overload, emotional demands, and hassles were associated with job burnout; and the job resources of opportunities for development, autonomy, feedback, and comfort at work were associated with work engagement. The perceptions of having limited job resources increased the operators' probability of suffering job burnout and vice versa. 


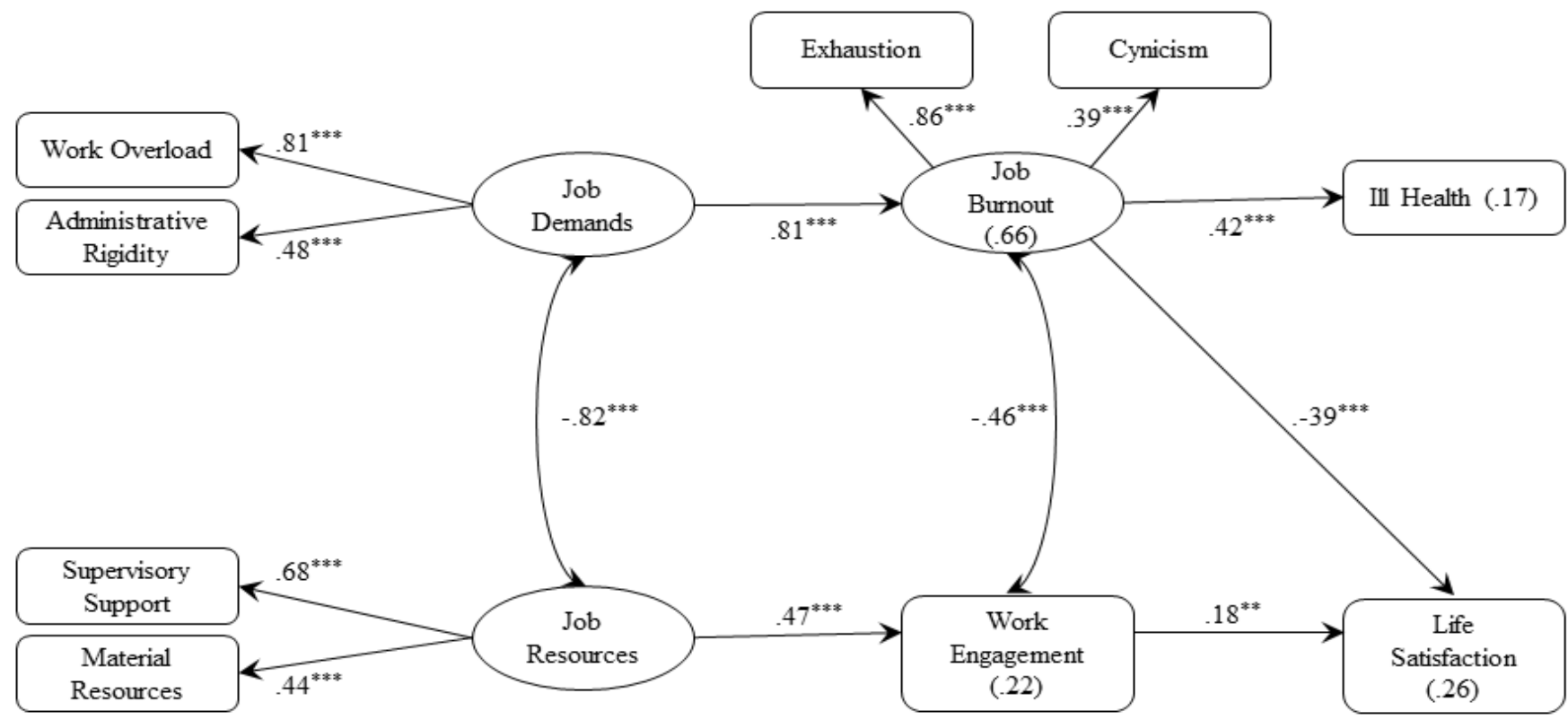

Figure 1. The JD-R model $(N=430)$. Note. ${ }^{* *} p<.001,{ }^{* *} p<.01$

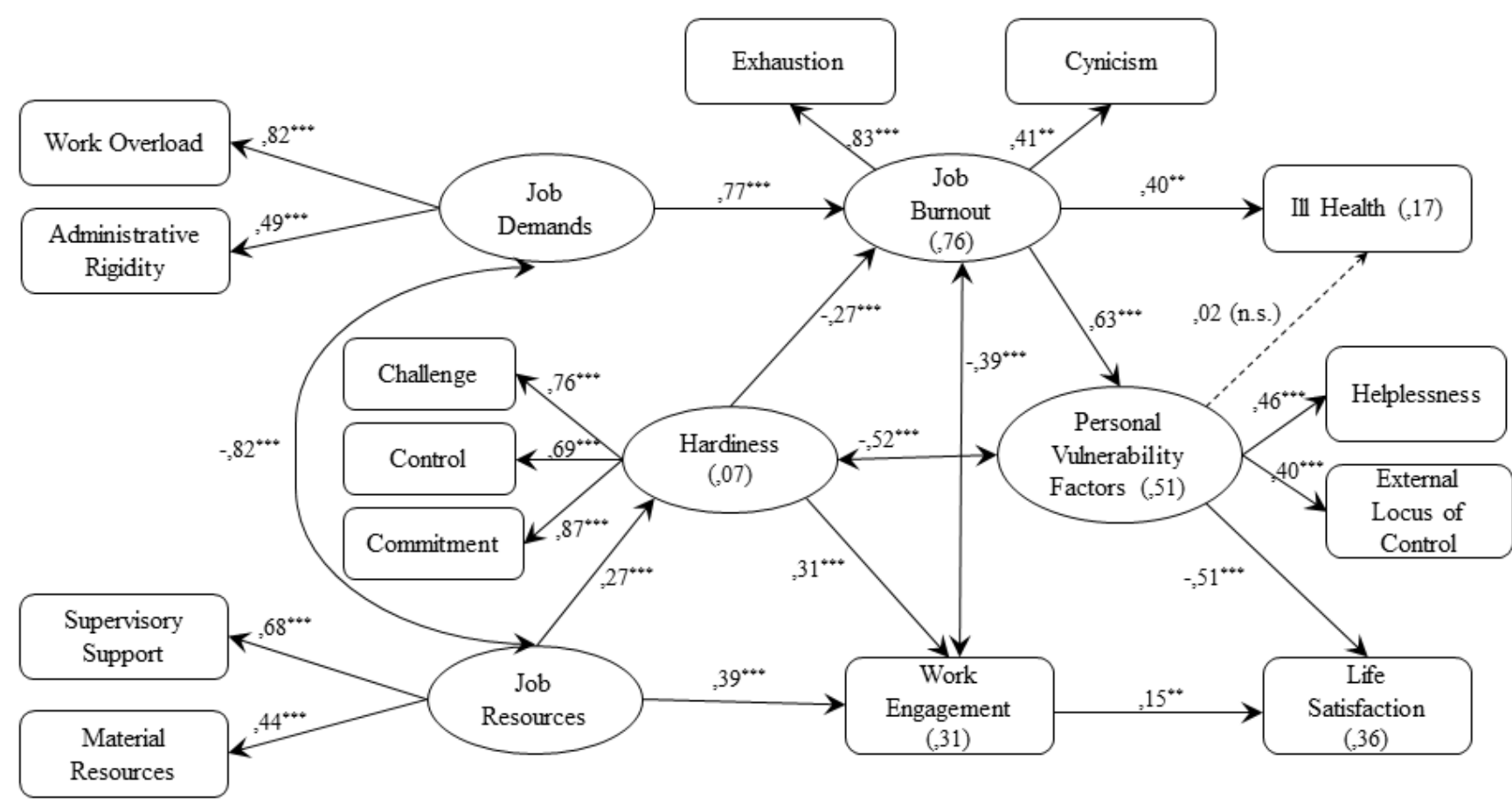

Figure 2. Hardiness and personal vulnerability factors in the $J D-R$ model $(N=430)$. Note. ${ }^{* *} p<.001,{ }^{* *} p<.01$, ${ }^{*} p<.05$ 
We found that job resources had an important role in stimulating job-crafting activities. Despite having a very structured job design, call operators engaged in job crafting activities such as increasing social job resources, increasing challenging job demands, and increasing structural job resources. In this study, the fourth job-crafting activity, reducing hindering demands, was not related to any situational factor. Contrary to what we expected, it was positively related to exhaustion and cynicism among the operators. This finding is in accordance with the findings of Petrou et al. [39], who also find positive associations between this dimension of job crafting and job burnout, suggesting that this might be a negative coping strategy in the long term because it results in less stimulating environments.

Job demands, as a whole, also had an effect on job crafting activities. In this case, the effect, despite being significant, was more discreet. However, when we analysed these separately we only found a negative association between hassles and increasing social job resources, which means that the more hassles an operator experienced, the less crafting of social job resources they practiced.

Job crafting activities had a positive effect on wellbeing at work, as it was positively associated with work engagement among the call centre operators and negatively associated with job burnout. Moreover, crafting one's job acted as a mediator between job resources and work engagement and between job resources and job burnout. These results are also in accordance with the COR theory, which states that to stay engaged, individuals must have the personal capacity as well as the environmental capacity to invest [40].

On the other hand, we found indirect effects of job crafting activities in the relationship between job demands and job burnout. In this case, the effect was discreet. These results ae consistent with the COR theory [40]. As regards the health impairment process, individuals take a conservative approach to resource investment, given that demands are high and the resources with which to tackle them are low. The job-crafting activity of the operators that was most negatively associated with exhaustion and cynicism was increasing structural job resources.

It is interesting to observe that call centre operators managed to take a proactive role at work by crafting their job, despite working in a highly controlled and structured work environment. Their perceived job resources had a positive impact on their job crafting activities. The present study suggests that it is possible to improve call centre conditions by investing more in providing operators with the adequate job resources and by giving them the possibility to practice job-crafting activities.

\section{Limitations}

The main limitation in this study stem from its cross-sectional nature. The use of structured equation modelling statistical techniques encourages causal inferences; however, such observations of causality should be taken with caution. To confirm the proposed processes, longitudinal studies are necessary.

Second, all the measures used in this study come from self-reports. Therefore, there is a probability of self-assessment bias. To limit this bias, we ensured that those who participated in the study did so voluntarily and knew that their responses would be treated with confidentiality. Nevertheless, selfreports are considered to be an effective method of evaluating perceptions and feelings (Sousa-Poza \& Sousa-Poza, 2000), such as job demands, job crafting and employee well-being.

Finally, the study used the convenience sampling technique, and this could result in low external validity. However, we made sure that a large number of outbound call centre operators took part in the study in order to improve the prospects of generalizing the results.

\section{References}

[1] ILO, Employment relationships in telecommunications services and in the call centre industry. (International International Labour Office, Geneva, 2015).

[2] S. Deery, R. Iverson, \& J. Walsh. Journal of Management Studies 39 (2002) 471-496.

[3] M. Houlihan. Journal of European Industrial Training 24 (2000), 228-240.

[4] J. Singh. Journal of Marketing 64 (2000) 1534.

[5] S. Choi, K. Cheong, \& R.A. Feinberg. Managing Service Quality 22 (2012) 492516 , http://dx.doi.org/10.1108/0960452121128139 6.

[6] S. Johnson, C. Cooper, S. Cartwright, I. Donald, P.J. Taylor, \& C. Millet. Journal of Managerial Psychology 20 (2005) 178-187.

[7] D. Zapf, A. Isic, M. Bechtoldt, \& P. Blau. 
European Journal of Work and Organizational Psychology 12 (2003) 311340.

[8] S. Grebner, N. Semmer, L. de Faso, S. Gut, W. Kälin, \& A. Elfering. European Journal of Work and Organizational Psychology 12 (2003) 341-365.

[9] M. Rod, \& N.J. Ashill. Managing Service Quality: An International Journal 23 (2013) 245-264.

[10] J.J. Hakanen, A.B. Bakker, \& W.B. Schaufeli, Journal of School Psychology 43 (2006) 495-513.

[11] V. Gonzáles-Romá, W.B. Schaufeli, A.B. Bakker, \& S. Lloret. Journal of Vocational Behavior 68 (2006) 165-174.

[12] W. Schaufeli. What is engagement? In C. Truss, K. Alfes, R. Delbridge, A. Shantz. Employee Engagement in Theory and Practice (Routledge, London, 2013), p.1-37.

[13] W. Khan. Human Relations 45 (1992) 321349.

[14] C.A. Sprigg, \& P.R. Jackson. Journal of Occupational Health Psychology 11 (2006) 197-212.

[15] M. Tims, A.B. Bakker, \& D. Derks. Journal of Vocational Behavior 80 (2012) 173-186.

[16] A. Wrzesniewski, \& J.E. Dutton. The Academy of Management Review 26 (2001)179-201.

[17] C. Maslach, \& M. P. Leiter. Journal of Applied Psychology 93 (2008) 498-512.

[18] WB. Schaufeli, A.B. Bakker, \& M. Salanova. Educational and Psychological Measurement, 66 (2006) 701-706.

[19] C. Maslach, \& M.P. Leiter. World Psychiatry 15 (2016) 103-111.

[20] W.B. Schaufeli, \& A.B. Bakker. Journal of Organizational Behavior 25 (2004) 293-315.

[21] A.B. Bakker, E. Demerouti, A.I. Sanz-Vergel. Annu. Rev. Organ. Psychol. Organ. Behav. 1 (2014) 389- 411.

[22] T.F. Meijman, \& G. Mulder. Psychological aspects of workload. In P. \&. Drenth, Handbook of work and organizational psychology (Psychology Press, Hove, 1998), p. 5-33.

[23] W.B. Schaufeli, \& A.B. Bakker. Test manual for the Utrecht Work Engagement Scale. (Utrecht University, the Netherlands, 2003). Unpublished manuscript. Obtenido de http://www.schaufeli.com

[24] A.B. Bakker, \& E. Demerouti. Job DemandsResources Theory. In: P. Y. Cooper, Work and Wellbeing: Wellbeing: A Complete Reference Guide, (John Wiley \& Sons, The
Netherlands, 2014), p.1-28.

[25] W.B. Schaufeli, \& T.W. Taris. A Critical Review of the Job Demands-Resources Model: Implications for Improving Work and Health. In a. H. Bauer G.F., Bridging Occupational, Organizational and Public Health: A Transdisciplinary Approach (Springer Science + Business Media Dordrecht, Dordrecht, 2014), p. 43-68.

[26] J.R. Halbesleben. A meta-analysis of work engagement: Relationships with burnout, demands, resources, and consequences.

[27] In A. Bakker \& M. Leiter, Work engagement A handbook of essential theory and research, (Psychology Press, New York, 2010), p. 102-117.

[28] A. Mustosmäki, T. Anttila, \& T. Oinas. Nordic journal of working life studies 3 (2013) 49-67.

[29] M. Tims, A.B. Bakker, \& D. Derks. Journal of Occupational Health Psychology 18 (2013) $230-240$.

[30] G.R. Oldham, \& Y. Fried. Organizational Behavior and Human Decision Processes 136 (2016) 20-35.

[31] A. Wrzeneiwski, N. LoBuglio, J.E. Dutton, \& J.M. Berg. Advances in Positive Organizational Psychology 1 (2013) 281302.

[32] E. Demerouti. European Psychologist 19 (2014) 237-247.

[33] G.P. McClelland, D.J. Leach, C.W. Clegg, \& I. McGowan. Journal of Occupational and Organizational Psychology 87 (2014) 464486.

[34] G. Slemp, M. Kern, \& D. Vella-Brodrick. Psychology of Well-Being 7 (2015) 1-17.

[35] P.M. Le Blanc, E. Demerouti, \& A.B. Bakker. How Can I Shape My Job to Suit Me Better? Job Crafting for Sustainable Employees And Organizations: An International Perspective. In N. F. Chmiel, An introduction to work and organizational psychology: An international perspective (Wiley, New York, 2017), p. 4863.

[36] P. Petrou, E. Demerouti, M.C. Peeters, W.B. Schaufeli, J. Hetland. Journal of Organizational Behavior 33 (2012) 11201141.

[37] E. Demerouti, A.B. Bakker, F. Nachreiner, \& W.B. Schaufeli. Journal of Applied Psychology 86 (2001) $499-512$.

[38] L.K. Harju, J.J. Hakanen, \& W.B. Schaufeli. Journal of Vocational Behavior 95-96 (2016) 11-20.

[39] S. Hobfoll. Conservation of resources theory: Its implication for stress, health, and 
resilience. In S. Folkman, The Oxford handbook of stress, health, and coping (Oxford University Press, Oxford, 2012), p. 1-42.

[40] P. Petrou, E. Demerouti, \& W.B. Schaufeli. Journal of Occupational Health Psychology 20 (2015) 470-480.

[41] S.E. Hobfoll, S.E. Conservation of Resources Theory: Its Implication for Stress, Health, and Resilience. In S. Folkman, The Oxford Handbook of Stress, Health, and Coping (Universidad Autónoma de Madrid, Madrid, 2010) p.1-42.
[42] W.B. Schaufeli, M.P. Leiter, C. Maslach, \& S.E. Jackson. Maslach Burnout InventoryGeneral Survey. In C. Maslach, S.E. Jackson, M.P. Leiter (Eds.), Maslach Burnout Inventory-Test manual (Consulting Psychologists Press, Palo Alto, 1996), p. 2226.

[43] A. Bakker.The Job Demands-Resources Questionnaire (Rotterdam, Erasmus University, 2014).

[44] Ministerio de Salud del Perú. Metodología para el estudio del clima organizacional. (MINSA, Lima, 2009).

[45] M. Tims, \& A.B. Bakker. Journal of Industrial Psychology 36 (2010) 1-9.

E-mail: sm.corsoo@up.edu.pe

I.lazartearanguren@up.edu.pe 